\title{
Long-term variations in outgoing long-wave radiation (OLR), convective available potential energy (CAPE) and temperature in the tropopause region over India
}

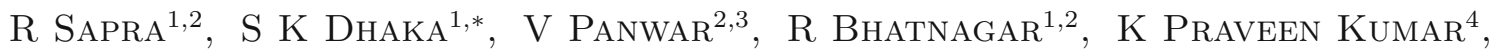 \\ Y Shibagaki ${ }^{5}$, M VEnKaT RATNAM ${ }^{6}$ and M TAKAHAShi ${ }^{7}$ \\ ${ }^{1}$ Radio and Atmospheric Physics Lab, Department of Physics, Rajdhani College, \\ University of Delhi, New Delhi, India. \\ ${ }^{2}$ Department of Physics and Astrophysics, University of Delhi, Delhi, India. \\ ${ }^{3}$ Radio and Atmospheric Science Division, National Physical Laboratory, New Delhi, India. \\ ${ }^{4}$ ISRO Headquarters, Antariksh Bhavan, New BEL Road, Bangalore 560 094, India. \\ ${ }^{5}$ Osaka Electro-Communication University, Osaka, Japan. \\ ${ }^{6}$ National Atmospheric Research Laboratory (NARL), Gadanki, India. \\ ${ }^{7}$ Atmosphere and Ocean Research Institute, University of Tokyo, Tokyo, Japan. \\ ${ }^{*}$ Corresponding author. e-mail: skdhaka@gmail.com
}

Relationship of outgoing long-wave radiation (OLR) with convective available potential energy (CAPE) and temperature at the $100-\mathrm{hPa}$ pressure level is examined using daily radiosonde data for a period 19802006 over Delhi $\left(28.3^{\circ} \mathrm{N}, 77.1^{\circ} \mathrm{E}\right)$ and Kolkata $\left(22.3^{\circ} \mathrm{N}, 88.2^{\circ} \mathrm{E}\right)$, and during $1989-2005$ over Cochin $\left(10^{\circ} \mathrm{N}\right.$, $\left.77^{\circ} \mathrm{E}\right)$ and Trivandrum $\left(8.5^{\circ} \mathrm{N}, 77.0^{\circ} \mathrm{E}\right)$, India. Correlation coefficient $\left(R_{\mathrm{xy}}\right)$ between monthly OLR and CAPE shows a significant $(\sim-0.45)$ anti-correlation at Delhi and Kolkata suggesting low OLR associated with high convective activity during summer (seasonal variation). Though, no significant correlation was found between OLR and CAPE at Cochin and Trivandrum (low latitude region); analysis of OLR and temperature (at $100-\mathrm{hPa}$ ) association suggests that low OLR peaks appear corresponding to low temperature at Delhi $\left(R_{\mathrm{xy}} \sim 0.30\right)$ and Kolkata $\left(R_{\mathrm{xy}} \sim 0.25\right)$ during summer. However, $R_{\mathrm{xy}}$ between OLR and temperature becomes opposite as we move towards low latitudes $\left(\sim 8^{\circ}-10^{\circ} \mathrm{N}\right)$ due to strong solar cycle influence. Large scale components mainly ENSO and quasi-biennial oscillaton (QBO) that contributed to the $100-\mathrm{hPa}$ temperature variability were also analyzed, which showed that ENSO variance is larger by a factor of two in comparison to QBO over Indian region. ENSO warm conditions cause warming at 100-hPa over Delhi and Darwin. However, due to strong QBO and solar signals in the equatorial region, ENSO signal seems less effective. QBO, ENSO, and solar cycle contribution in temperature are found location-dependent (latitudinal variability) responding in consonance with shifting in convective activity regime during El Niño, seasonal variability in the tropical easterly jet, and the solar irradiance.

\section{Introduction}

In a recent study, Dhaka et al (2010) have analyzed relation between convective available potential energy (CAPE) and temperature in the tropopause region suggesting that the increase in convective activity is associated with the decrease in temperature at 100-hPa pressure level on seasonal as well

Keywords. Convective available potential energy (CAPE); outgoing long-wave radiation (OLR); tropopause; solar cycle; quasi-biennial oscillation (QBO); El Niño/southern oscillation (ENSO). 
as on inter-annual scale. They have also examined the presence and latitudinal variation of solar cycle signal in temperature at $100-\mathrm{hPa}$ level $(\sim 16 \mathrm{~km})$ proving that solar cycle effect on the temperature is most dominating at stations which are located around $8^{\circ}-10^{\circ} \mathrm{N}$. Thus, temperature variations in the upper troposphere are found to be jointly controlled by CAPE and solar cycle showing their respective contribution depending on the location of observed station.

Recently, Jain et al (2010) examined the relative spatial distribution of outgoing long-wave radiation (OLR) and $\mathrm{T}_{100}$ (temperature at $100-\mathrm{hPa}$ level) using daily mean OLR (obtained from NOAA) and daily mean $\mathrm{T}_{100}$ field (taken from NCEP reanalysis) over a period of 24 June-15 August 2002 covering Bay of Bengal (BOB: $10^{\circ}-20^{\circ} \mathrm{N}, 85^{\circ}-90^{\circ} \mathrm{E}$ ) region. In this context, they observed that low $\mathrm{T}_{100}$ and low OLR occur over the same broad area, though all OLR and low $\mathrm{T}_{100}$ areas do not overlap. It may be mentioned here that in such cases, OLR is greater than $160 \mathrm{Wm}^{-2}$ at the location of low $\mathrm{T}_{100}$. However, in some cases, some of the low OLR and low $\mathrm{T}_{100}$ areas are found to be overlapped or partially overlapped. This analysis was performed over two specific regions: Indian landmass (ILM: $10^{\circ}-20^{\circ} \mathrm{N}, 72.5^{\circ}-82.25^{\circ} \mathrm{E}$ ) and Bay of Bengal (BOB: $\left.10^{\circ}-20^{\circ} \mathrm{N}, 85^{\circ}-90^{\circ} \mathrm{E}\right)$.

In a further study, Jain et al (2011) examined the monthly variation for observing spatial occurrence of the area of low CPT (cold point tropopause) temperature and that of low OLR using COSMIC satellite observations during the year 2007 over $0^{\circ}-30^{\circ} \mathrm{N}$ and $40^{\circ}-120^{\circ} \mathrm{E}$, i.e., covering BOB, Arabian Sea, and adjoining areas which often extend to the Africa's Horn region. They observed that both the low CPT temperature and low OLR occur at the northern latitudes in the summer monsoon season (May-September) and in the postmonsoon season (i.e., October). Almost similar patterns prevail though locations of low OLR and low CPT temperature move closer to the equator. However, there is a lack of information on the relationship of OLR and temperature at 100-hPa level on large scale (covering several years) over Indian region.

OLR is an important parameter for understanding the deep and wide atmospheric convection. The OLR association with CAPE and temperature at $100-\mathrm{hPa}$ level on Indian region is not yet investigated as performed for other parameters in the analysis by Dhaka et al (2010). Thus, we intend to examine in this study as to how OLR relates with the CAPE and temperature at 100-hPa level on seasonal, annual, and large scale (up to decadal scale) over Indian region. In addition, the contribution of individual components such as El Niño/ southern oscillation (ENSO) and quasi-biennial oscillation (QBO) to the temperature variation is examined over Indian region and at two nearby stations located at the eastern side of Bay of Bengal that covers partly the Indonesian region.

Randel et al (1999) observed that the QBO temperature anomalies have a symmetrical structure centered over the equator $\left(\sim 10^{\circ} \mathrm{N}-\mathrm{S}\right)$, with variations of order $\pm 4 \mathrm{~K}$ near 30 mbar and $\pm 1 \mathrm{~K}$ at 70 mbar. In their further study (Randel et al 2000), the prominent signatures of the QBO and ENSO events are observed in the temperature and pressure at tropopause region. The statistical QBO signal for the periods $1958-1978$ and $1979-1997$ is noted of the order of $\pm 0.6 \mathrm{~K}$ and $\pm 0.3 \mathrm{~K}$ with positive tropopause temperatures associated with positive (westerly) QBO winds at 50 mbar using 26 tropical stations excluding Indian region. ENSO tropopause variations were also found evident as an east-west seesaw over the western and central Pacific Ocean with local maximum anomalies of order $\pm 2-3 \mathrm{~K}$ and $\pm 4-6$ mbar for temperature and pressure, respectively.

But there was no such effort made to examine the communication of ENSO event in the upper troposphere to the large distances such as over India. Therefore, the current study over Indian region assumes significance.

In this study, we have selected $100-\mathrm{hPa}$ level to measure QBO and ENSO signals in temperature. We compared ENSO signature in temperature between the Indian region and at Darwin station (Darwin station clearly show the response of ENSO).

For studying the relation of OLR with CAPE and temperature at $100-\mathrm{hPa}$, we used long term data of OLR, CAPE and temperature at four stations namely Delhi, Kolkata, Cochin and Trivandrum, which are latitudinally separated representing northern, eastern and southern regions, respectively. In addition, to examine the effect of each of ENSO and QBO in temperature we have included few more stations such as Bombay and Vishakhapatnam over India, and Kota Bharu and Singapore in the eastern side of Bay of Bengal. Data and analysis are mentioned in section 2 . Results and discussion are shown in section 3, and summary is given in section 4 .

\section{Data and method of analysis}

We used National Center for Environmental Prediction (NCEP) daily OLR data for a period 1980 to 2006 at Delhi, Kolkata, Cochin and Trivandrum stations for showing its long term variability. Monthly mean time series was obtained by averaging the daily values. We have made use of 27 years of daily radiosonde data at Delhi and Kolkata stations from 1980 to 2006 and 
Table 1. Latitude and longitude of stations over Indian and eastern side of Bay of Bengal region that are used in the study.

\begin{tabular}{lcr}
\hline Stations & Latitude and longitude & Data length \\
\hline Delhi & $28.3^{\circ} \mathrm{N}, 77.1^{\circ} \mathrm{E}$ & $1980-2006$ \\
Kolkata & $22.3^{\circ} \mathrm{N}, 88.2^{\circ} \mathrm{E}$ & $1980-2006$ \\
Bombay & $19.11^{\circ} \mathrm{N}, 72.84^{\circ} \mathrm{E}$ & $1989-2006$ \\
Vishakhapatnam & $17.0^{\circ} \mathrm{N}, 83.30^{\circ} \mathrm{E}$ & $1989-2006$ \\
Cochin & $10.0^{\circ} \mathrm{N}, 77.0^{\circ} \mathrm{E}$ & $1989-2005$ \\
Trivandrum & $8.5^{\circ} \mathrm{N}, 77.0^{\circ} \mathrm{E}$ & $1989-2005$ \\
Kota Bharu & $6.15^{\circ} \mathrm{N}, 102.27^{\circ} \mathrm{E}$ & $1989-2006$ \\
Singapore & $1.36^{\circ} \mathrm{N}, 103.9^{\circ} \mathrm{E}$ & $1989-2006$ \\
\hline
\end{tabular}

about 18 years of radiosonde data at Bombay, Vishakhapatnam, Cochin, Trivandrum, Kota Bharu and Singapore stations for a period 19892006 at 1200 hrs GMT for showing temperature variation at $100-\mathrm{hPa}$ level. Above stations are selected based on extended study in the Indian and eastern side of Bay of Bengal regions. Information regarding latitude and longitude of the stations along with their data length are mentioned in table 1 . Routine radiosonde temperature data at 100-hPa level, a height of tropopause region, were acquired by India Meteorological Department (IMD), Delhi. The error in the basic temperature measurements, due to the temperature sensor as given by IMD, is expected to be $\sim 1 \mathrm{~K}$. Monthly mean CAPE and $100-\mathrm{hPa}$ temperature data over four stations (Delhi, Kolkata, Cochin and Trivandrum) are used from a companion paper (Dhaka et al 2010). Following formulation is used to compute CAPE.

$$
\mathrm{CAPE}=g \int_{Z=L F C}^{Z=L N B} \frac{\left(T_{p}-T_{e}\right)}{T_{e} d z}
$$

where $T_{p}$ is the temperature of a parcel from the lowest $500 \mathrm{~m}$ of the atmosphere raised dry adiabatically to the lifted condensation level (LCL) and moist adiabatically thereafter, and $T_{e}$ is the temperature of the environment. This expression is integrated over the sounding layers from the level of free convection (LFC) to the level of neutral buoyancy (LNB) for which $\left(T_{p}-T_{e}\right)$ is greater than zero. The LNB denotes a level at which a parcel from the lowest $500 \mathrm{~m}$ of the atmosphere is raised dry adiabatically to the LCL and moist adiabatically to a level above which the temperature of the parcel is the same as the environment. If more than one equilibrium level exists, the highest one is chosen. If more than one LFCT exists, the lowest level is chosen. There are other methods also, which can be used to compute CAPE from radiosonde data as suggested and discussed by William and
Renno (1993), Mc Bridge and Frank (1999), Gettelman et al (2002) and, recently by Roy Bhowmik et al (2008). The estimates of CAPE in these studies are somewhat different, primarily due to the assumption made in the computation.

Monthly averaged sunspot number and standardized southern oscillation index (SOI) data are obtained from NASA (http://www.nasa.gov). In order to examine the individual contribution of QBO, ENSO and solar cycle in the 100-hPa temperature variations, we applied filters in the temperature data. For instance, to find contribution of QBO signal we removed ENSO, solar cycle and other components from the temperature variations, and similar exercise is performed for other filtered components.

\section{Results and discussion}

\subsection{Relationship of OLR with CAPE and temperature at the 100-hPa level over Delhi, Kolkata, Cochin and Trivandrum stations}

In this section, association of OLR with CAPE and temperature is examined. The monthly averaged OLR, CAPE and 100-hPa temperature variations for a period 1980-2006 at Delhi and Kolkata and over a period 1989-2005 at Cochin and Trivandrum are shown in figures $1-4$. In figures $1-4$, top panels show temperature variations, middle panels show OLR variations, while CAPE variations are shown in the bottom panels.

Observing OLR and CAPE variations at Delhi, we found a single annual broad peak in CAPE around July-August with a clear annual variability in occurrence of low OLR. In more than $90 \%$ of the cases, low OLR coincides with enhanced CAPE value. During monsoon season, low OLR corresponds to the large convective activity. In order to assess the relationship between OLR and CAPE, correlation coefficient $\left(R_{\mathrm{xy}}\right)$, is computed between them using monthly data, which is $\sim-0.43$ (at $1 \%$ significance level). $R_{\mathrm{xy}}$ indicates that anticorrelation exists between OLR and CAPE variations at Delhi, which is consistent with low OLR induced due to summer monsoon and increased convective activity. A clear annual variability in temperature is consistent with OLR and CAPE. Linear trends in OLR are not significant over a given period (not shown). On close inspection of OLR and temperature monthly variations at Delhi, we observed that in most of the years low OLR values correspond to the dip in temperature (by 5-8 K from mean) suggesting that low OLR favours cooling in the tropopause region. The significant positive value of correlation coefficient $\left(R_{\mathrm{xy}} \sim 0.30\right)$ and matching of low OLR with dip in temperature 


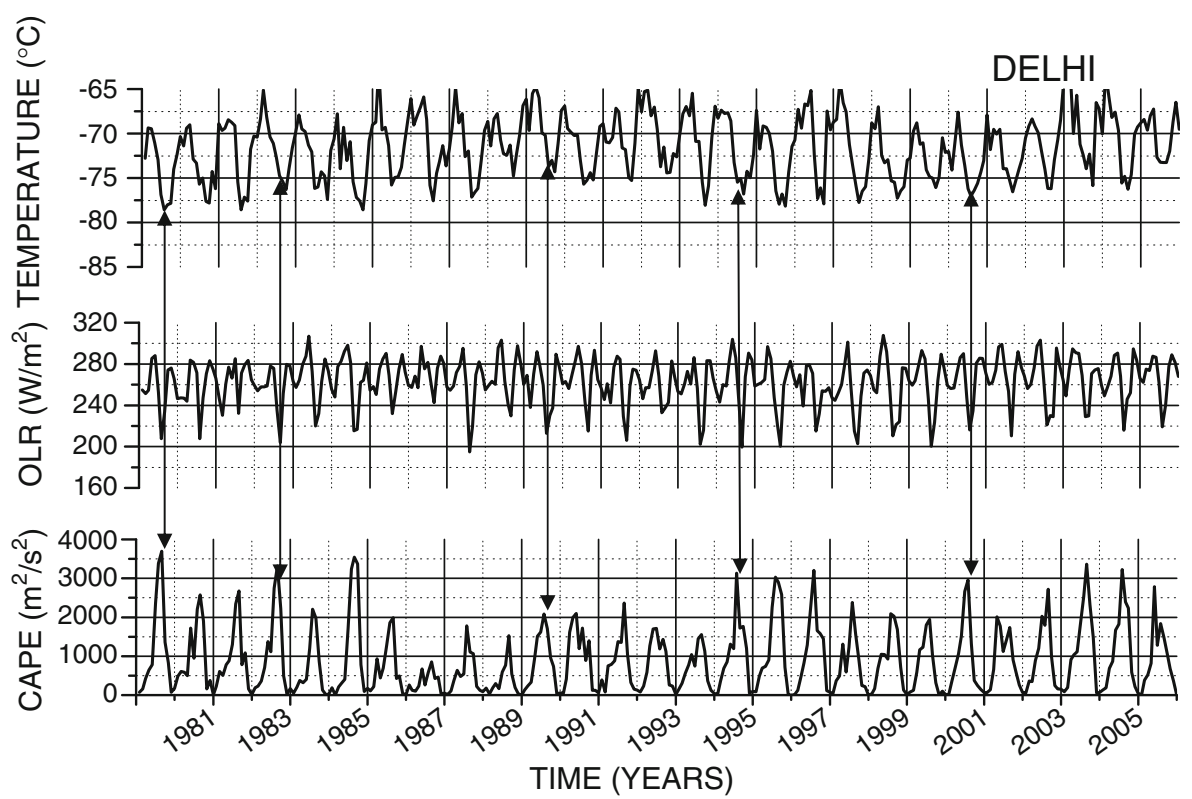

Figure 1. Monthly mean temperature at the 100-hPa level (top panel), OLR (middle panel) and monthly mean CAPE (bottom panel) is plotted for a period 1980-2006 at Delhi.

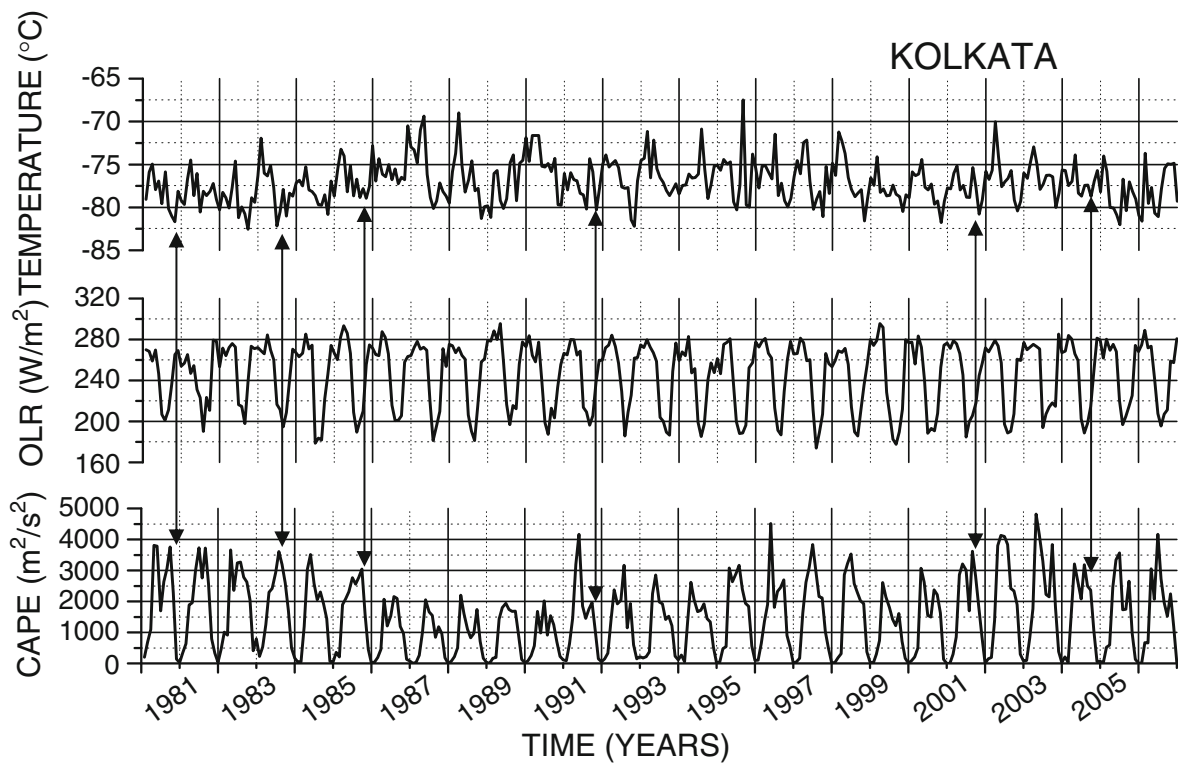

Figure 2. Same as figure 1, but at Kolkata station.

(in figure 1) suggest a close association between them.

Similarly temporal variation of OLR, CAPE and temperature at Kolkata is shown in figure 2. CAPE shows bimodal character instead of a single strong peak as found over Delhi. The primary peaks occur during pre-monsoon (April-May) and monsoon (June-September) period. Peaks in premonsoon/monsoon period are stronger than those appeared in October. Whereas single annual dip in OLR is noted during July-August months similar to as found over Delhi station. The enhanced
CAPE (in post-monsoon season) coincides with low OLR. Also anti-correlation between OLR and CAPE is high (see table 2a) at Kolkata station. This is due to the fact that convection stays longer at Kolkata as it is located in the close vicinity of Bay of Bengal region. Similar to CAPE, the annual peaks in temperature are not the broader one; rather they appear in the form of primary and secondary maxima. In $50 \%$ of the cases, low OLR corresponds to low temperature in the tropopause region. Correlation coefficient $\left(R_{\mathrm{xy}} \sim\right.$ 0.25 ) between OLR and temperature is significant; 


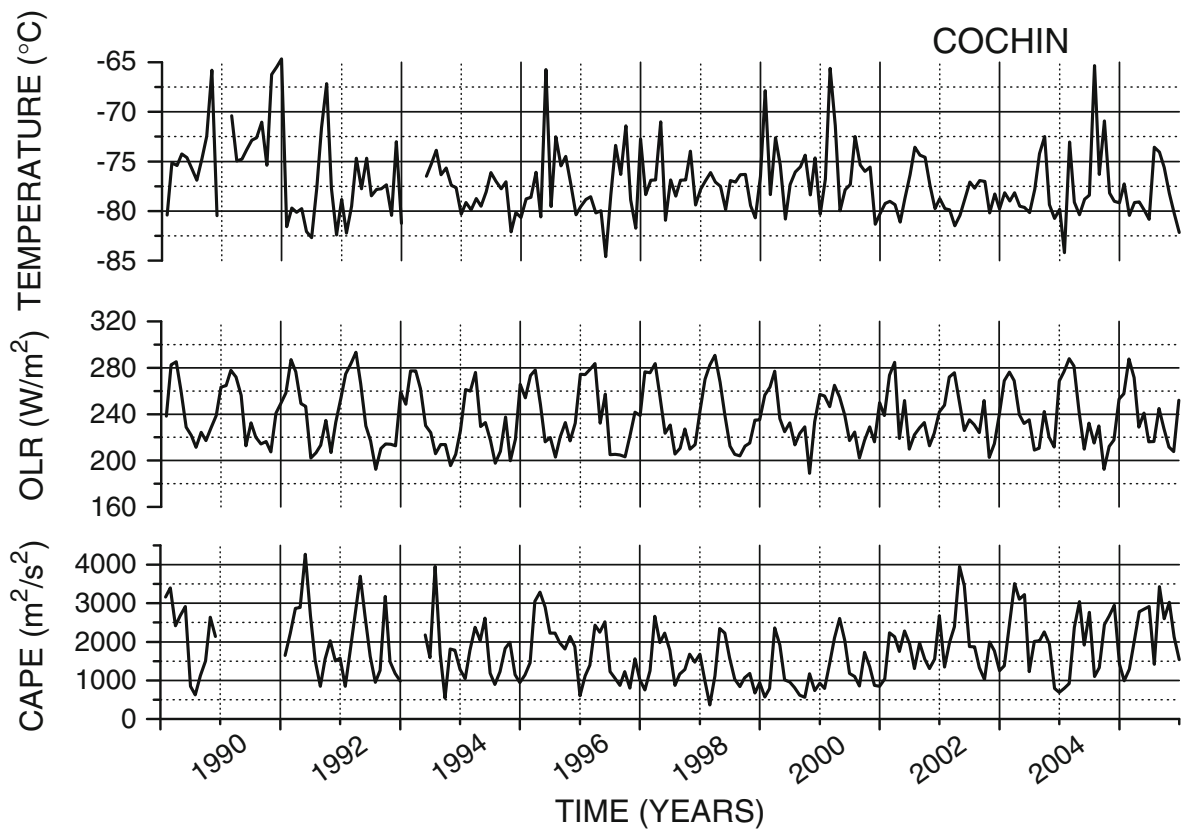

Figure 3. Monthly mean temperature at the 100-hPa level (top panel), OLR (middle panel) and monthly mean CAPE (bottom panel) is plotted for a period 1989-2005 at Cochin.

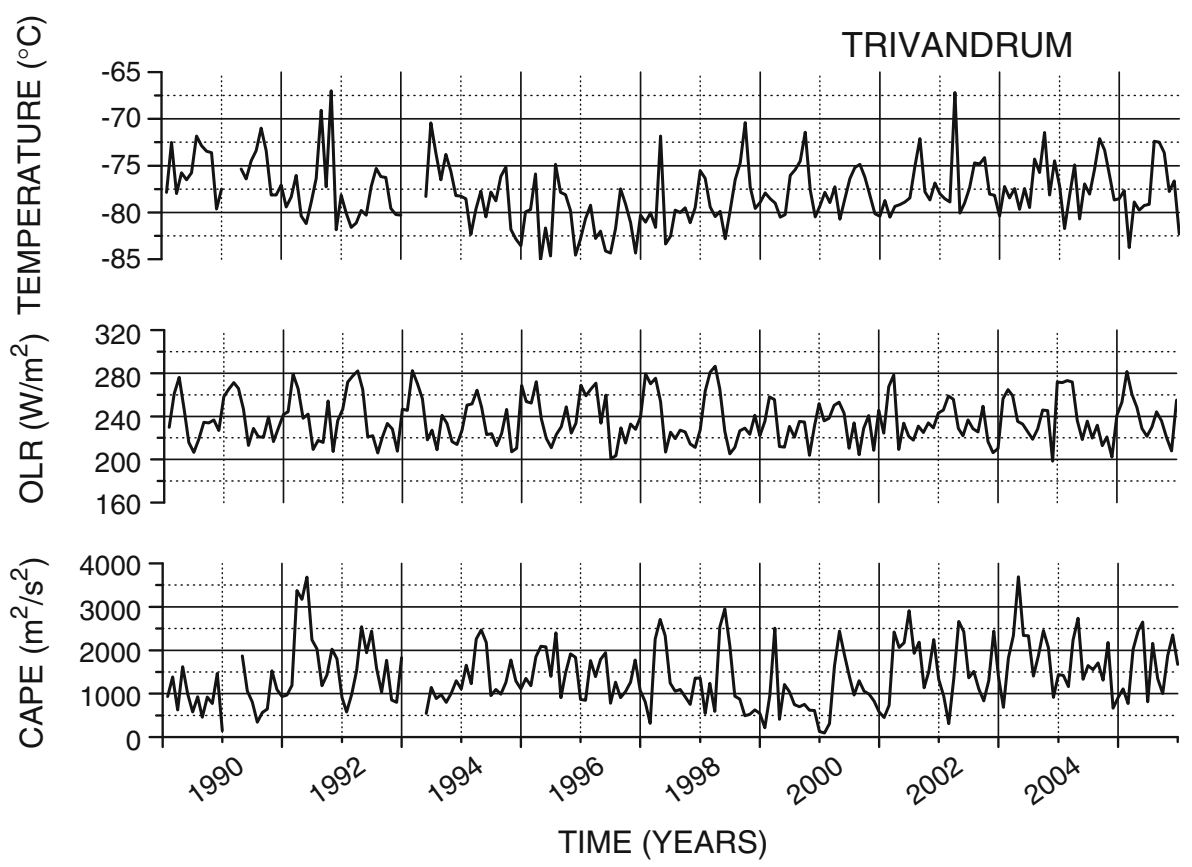

Figure 4. Same as figure 3, but at Trivandrum station.

however, it is lesser in comparison to Delhi station. In addition, the standard deviation in the monthly mean of OLR, CAPE and temperature is computed and shown in table 2(b). The standard deviation in OLR and CAPE is large at Kolkata station.

We extended this analysis by considering Cochin and Trivandrum stations over low latitude region. Figure 3 shows monthly OLR, CAPE and temperature variability over a period 1989-2005 at
Cochin. The bottom panel shows the CAPE variations. During most of the years twin peaks are noted in CAPE; first peak appear around AprilMay and the second one during October - postmonsoon period. Peaks during pre-monsoon and monsoon are stronger than those appeared during October. However, low OLR peaks occurred during July-August/October-November months. The relation of low OLR dips during October- 
Table 2(a). Correlation coefficients of monthly, high pass filtered (including solar cycle removed) with cut-off of 24 and 16 months and annual CAPE and temperature at 100-hPa level with OLR over Delhi, Kolkata, Cochin and Trivandrum stations. Bold values of $R_{\mathrm{xy}}$ are statistically significant (using student's t-test) at $1 \%$ significance level.

\begin{tabular}{|c|c|c|c|c|c|c|}
\hline \multirow[b]{2}{*}{ Stations } & \multicolumn{3}{|c|}{$\begin{array}{c}\text { Correlation coefficient }\left(R_{\mathrm{xy}}\right) \\
\text { between OLR and CAPE Data }\end{array}$} & \multicolumn{3}{|c|}{$\begin{array}{c}\text { Correlation coefficient }\left(R_{\mathrm{xy}}\right) \text { between } \\
\text { OLR and Temperature Data }\end{array}$} \\
\hline & $\begin{array}{l}\text { Using monthly } \\
\text { data }\end{array}$ & $\begin{array}{l}\text { Solar cycle } \\
\text { removed data }\end{array}$ & $\begin{array}{l}\text { Using annual } \\
\text { data }\end{array}$ & $\begin{array}{l}\text { Using monthly } \\
\text { data }\end{array}$ & $\begin{array}{l}\text { Solar cycle } \\
\text { removed data }\end{array}$ & $\begin{array}{l}\text { Using annual } \\
\text { data }\end{array}$ \\
\hline Delhi & -0.43 & -0.47 & -0.23 & 0.30 & 0.33 & 0.05 \\
\hline Kolkata & -0.47 & -0.34 & 0.09 & 0.25 & 0.24 & -0.21 \\
\hline Cochin & 0.12 & 0.05 & 0.42 & -0.15 & 0.15 & 0.05 \\
\hline Trivandrum & 0.03 & -0.06 & 0.36 & -0.16 & 0.23 & -0.07 \\
\hline
\end{tabular}

Table 2(b). Standard deviation in the monthly and annual mean estimates of OLR, CAPE and temperature over Delhi, Kolkata, Cochin and Trivandrum stations.

\begin{tabular}{|c|c|c|c|c|c|c|}
\hline \multirow[b]{2}{*}{ Stations } & \multicolumn{2}{|c|}{ Standard deviation of OLR } & \multicolumn{2}{|c|}{$\begin{array}{c}\text { Standard deviation } \\
\text { of CAPE }\end{array}$} & \multicolumn{2}{|c|}{$\begin{array}{c}\text { Standard deviation } \\
\text { of temperature }\end{array}$} \\
\hline & $\begin{array}{l}\text { Using monthly } \\
\text { data }\end{array}$ & $\begin{array}{l}\text { Using annual } \\
\text { data }\end{array}$ & $\begin{array}{l}\text { Using monthly } \\
\text { data }\end{array}$ & $\begin{array}{l}\text { Using annual } \\
\text { data }\end{array}$ & $\begin{array}{l}\text { Using monthly } \\
\text { data }\end{array}$ & $\begin{array}{l}\text { Using annual } \\
\text { data }\end{array}$ \\
\hline Delhi & 23.14 & 4.41 & 860.01 & 233.15 & 3.56 & 1.29 \\
\hline Kolkata & 33.00 & 3.73 & 1186.22 & 371.27 & 2.54 & 0.97 \\
\hline Cochin & 25.88 & 2.42 & 809.29 & 350.73 & 3.66 & 1.82 \\
\hline Trivandrum & 21.18 & 2.78 & 711.88 & 346.94 & 3.27 & 1.69 \\
\hline
\end{tabular}

November months with high CAPE values show mixed behaviour suggesting that OLR and CAPE relationship get modified at Cochin station. Moreover, the correlation coefficient between OLR and CAPE is insignificant which further indicates weak association between these two parameters. However, in case of OLR and 100-hPa temperature variations, it is found that decrease in OLR corresponds to increase in temperature at 100-hPa level. Also significant correlation coefficient between OLR and temperature is of the order of -0.15 indicating anti-correlation between these parameters. Thus, OLR-temperature relation shows different characteristics at Cochin in comparison to Delhi and Kolkata stations. This may be due to the presence of strong solar cycle signal in temperature variations at low latitudes (Dhaka et al 2010).

The temporal variation of OLR, CAPE and temperature at Trivandrum is shown in figure 4. Similar to Kolkata and Cochin stations, a bimodal behaviour in CAPE peaks is noted in most of the years with primary peaks occurring during premonsoon period followed by secondary peaks during post-monsoon around October. However, low OLR peaks are noted around June-July/OctoberNovember months. No relationship is seen between OLR and CAPE variations at Trivandrum station too indicating no significant linkages between them. The association of OLR and CAPE relationship towards low latitudes is strongly influenced due to the northward movement $\left(\sim 20^{\circ}-24^{\circ} \mathrm{N}\right)$ of inter-tropical convergence zone (ITCZ) during summer (June-July). During summer, ITCZ shifts to $20^{\circ}-24^{\circ} \mathrm{N}$, which is far from Cochin and Trivandrum locations but in close proximity to Delhi and Kolkata stations. This is in accord with the fact that the ITCZ is normally located in the region of $12^{\circ}-15^{\circ} \mathrm{S}$ in the month of January and during summer monsoon, the ITCZ merges with the monsoon trough and in the month of July, the ITCZ is located in the region of $\sim 20^{\circ}-24^{\circ} \mathrm{N}$ latitude range (Holton et al 2003). Therefore, relation between OLR and CAPE is linked with the location of ITCZ. On observing monthly averaged OLR and temperature variations, anti-correlation between OLR and temperature is noted similar to Cochin station indicating a dip in OLR that corresponds to the increase in temperature of the tropopause region. This suggests that large scale features (such as solar cycle) could modulate OLR and temperature relationship around $8^{\circ}-10^{\circ} \mathrm{N}$.

Further, in order to analyze relation between OLR-CAPE and OLR-temperature more evidently, numerical filtration method is used. Using this technique, solar cycle component was filtered out from the CAPE and temperature variations and correlation coefficient between OLR and filtered CAPE and OLR and filtered temperature variations was re-computed. But even after removing the solar cycle factor we could not find any significant relation between OLR and CAPE at Cochin and Trivandrum. Whereas at Delhi and Kolkata stations it is found that low OLR values are still associated with enhanced CAPE, which 
suggests strong anti-correlation between OLR and CAPE. Thus, low OLR leads to increase in convective activity at Delhi and Kolkata stations.

However, the analysis of OLR and filtered temperature variations indicates improvement in $R_{\mathrm{xy}}$ at Cochin and Trivandrum stations. Now, the correlation between OLR and filtered temperature (solar cycle signal removed) at $100-\mathrm{hPa}$ level turns positive at Cochin and Trivandrum similar to as observed over Delhi and Kolkata. However, the magnitude of $R_{\mathrm{xy}}$ is slightly less (though significant) at Cochin and Trivandrum in comparison to Delhi and Kolkata. Thus, OLR and temperature at the $100-\mathrm{hPa}$ level are positively correlated at all stations after removing the solar cycle signal from the temperature data. This further strengthens the fact that solar cycle component plays a dominant role in the $100-\mathrm{hPa}$ temperature variations around $8^{\circ}-10^{\circ} \mathrm{N}$.

\subsection{Composites of inter-annual variations in OLR, CAPE and temperature at 100-hPa level}

To examine OLR-CAPE and OLR-temperature relationship on an annual basis, we have considered yearly averaged OLR, CAPE and temperature data. Figure 5 shows the temporal variation of annually averaged OLR and CAPE data from 1980 to 2006 at Delhi and Kolkata and during 1989-2005 at Cochin and Trivandrum, while temporal variation of annual OLR and temperature at $100-\mathrm{hPa}$ level at these stations are shown in figure 6 . The correlation coefficient between annually averaged OLR and CAPE data and between OLR and temperature at the $100-\mathrm{hPa}$ level is computed at all stations and shown in table 2(a).

On analyzing correlation between annual OLR and CAPE variations, we found that the significant $R_{\mathrm{xy}}$ in case of monthly averaged values turn insignificant after yearly averaging OLR and CAPE data at Delhi and Kolkata stations. This shows that OLR and CAPE variations are mainly dominated by seasonal scale cycle. However, at Cochin and Trivandrum stations the magnitude of positive correlation between OLR and CAPE increases after removing the seasonal variations, but value of $R_{\mathrm{xy}}$ is still insignificant at Trivandrum, but significant at Cochin. Thus, we can conclude that the significant relationship (anti-correlation) between OLR and CAPE is based on the seasonal dominance at Delhi and Kolkata stations, which are away from the equatorial belt.

In case of yearly averaged OLR and temperature variations following features are noted. $R_{\mathrm{xy}}$ shows anti-correlation between OLR and 100-hPa temperature at Kolkata and Trivandrum; whereas

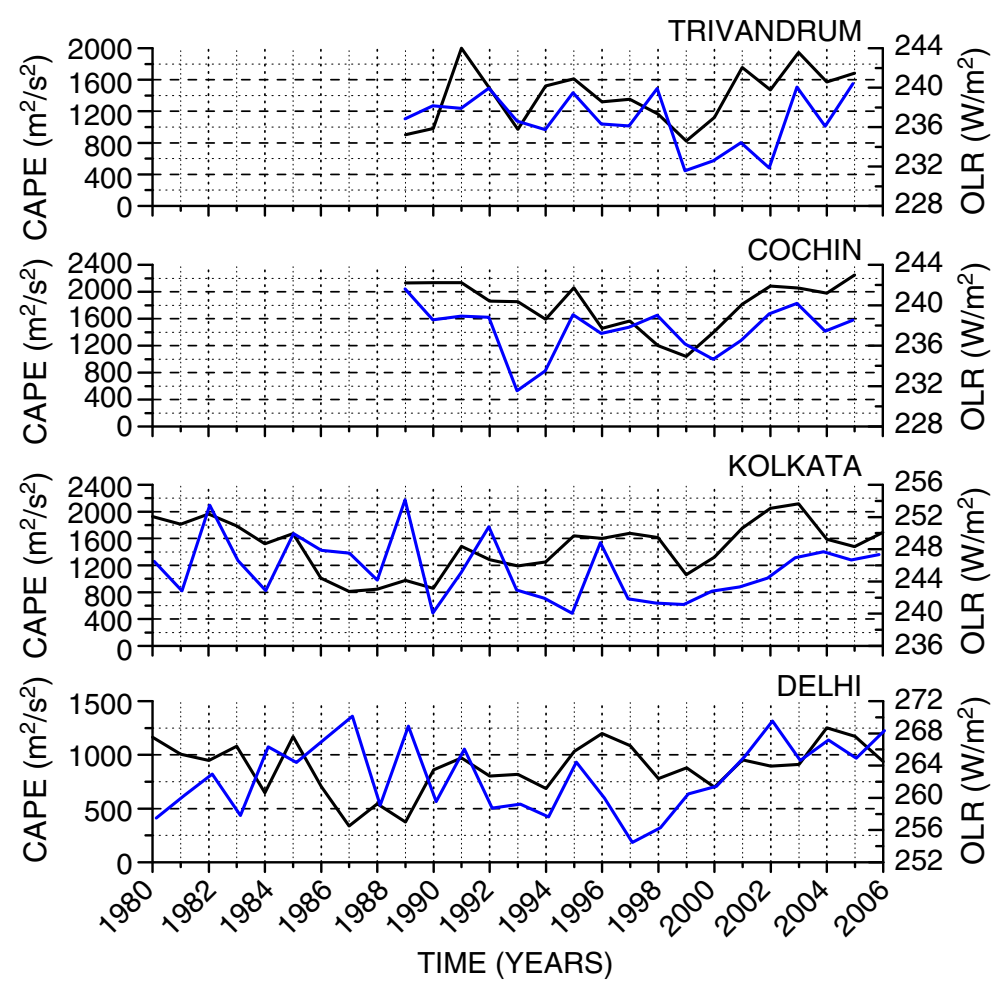

Figure 5. Temporal variation of yearly averaged OLR and CAPE (over a period of 1980-2006 at Delhi and Kolkata stations and during 1989-2005 at Cochin and Trivandrum). Black lines denote CAPE, while blue lines OLR. 


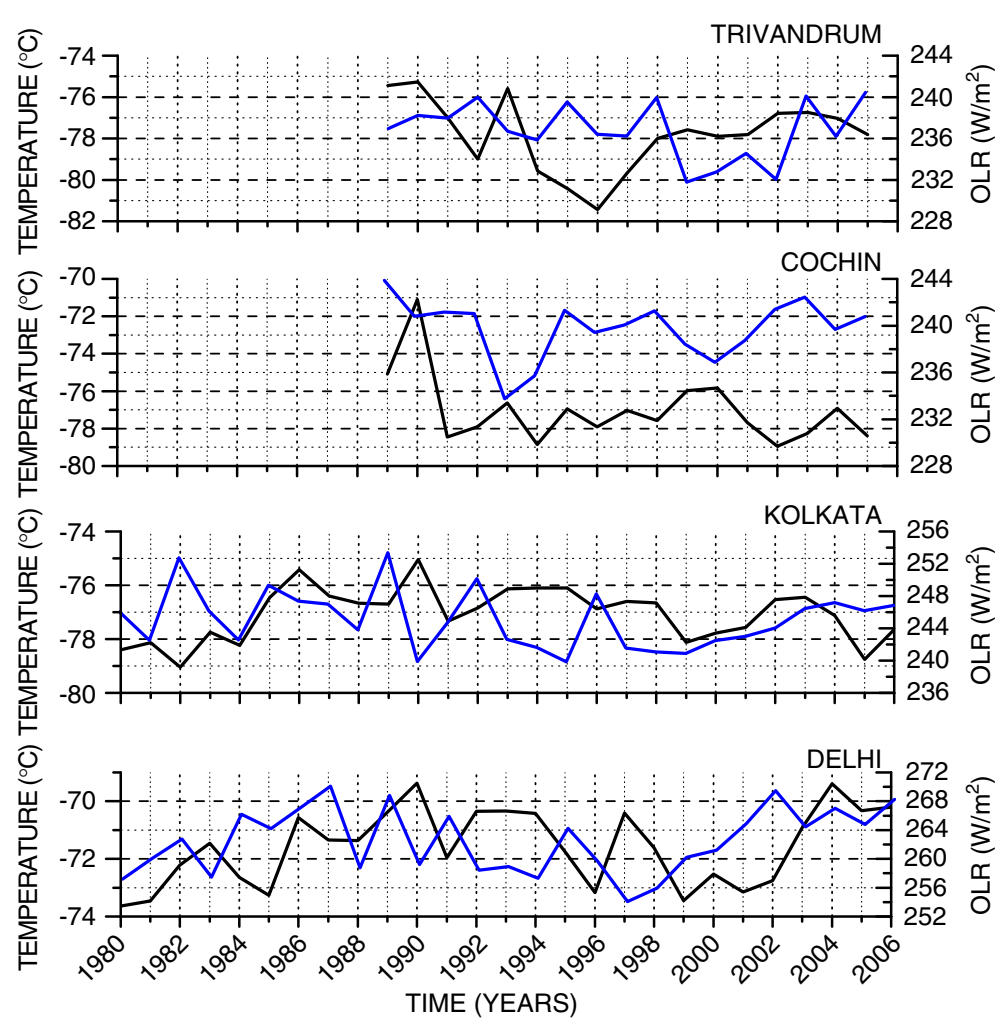

Figure 6. Temporal variation of yearly averaged OLR with temperature at 100-hPa level (over a period of 1980-2006 at Delhi and Kolkata and from 1989-2005 at Cochin and Trivandrum). Black lines denote temperature, while blue lines OLR.

the positive $R_{\mathrm{xy}}$ is reduced at Delhi and Cochin indicating that correlation coefficient values become unsystematic after removing the seasonal scale variations from OLR and temperature data. Moreover, the significant $R_{\mathrm{xy}}$ values in case of monthly averaged data turn insignificant for annually averaged data at all stations. This suggests that the positive significant relation between OLR and temperature is due to the presence of seasonal variations. From this analysis, we conclude that seasonal variability dominates in OLR-CAPE and OLR-temperature relationship on a long term basis.

\subsection{Signatures of long-term oscillations in temperature at 100-hPa level}

In general, the temperature field in the tropopause region is modulated by long term oscillations such as QBO, ENSO as shown by Randel et al (2000) in western pacific region. Observations of $\mathrm{QBO}$ and ENSO at $100-\mathrm{hPa}$ temperature over India are not yet completely analyzed to confirm the presence of similar components and delineate the mechanism involved. In this section, we have analyzed temperature data at eight stations, which are explained below.

\subsubsection{QBO in temperature at 100-hPa level}

To examine the individual contribution of QBO signal in the temperature at $100-\mathrm{hPa}$ pressure level, we filtered out solar cycle and ENSO components from the temperature data. That is, in order to find the influence of only QBO signal in the tropopause-temperature region, we removed all other components and retained periods between 25 and 35 months.

Figure 7 ( $\mathrm{a}$ and $\mathrm{b}$ ) shows filtered temperature (only QBO signal retained) at $100-\mathrm{hPa}$ level at Delhi, Kolkata, Bombay, Vishakhapatnam, Cochin, Trivandrum, Kota Bharu and Singapore stations representing Indian and eastern side of the Bay of Bengal region. At Delhi and Kolkata, we found a clean QBO variability $(\sim \pm 0.4 \mathrm{~K})$ in the temperature of the tropopause region during 19802006. QBO signal is found comparable at Delhi and Kolkata. This matches well with the ERA40 dataset (Pascoe et al 2005), which captured the QBO signal extremely well as compared to radiosonde data (Naujokat 1986) and rocketsonde data (Gray et al 2001). Pascoe et al (2005) also calculated the amplitude of the QBO $\left(\mathrm{ms}^{-1}\right)$ in the zonal mean zonal wind and observed that QBO zonal winds are present over the equator from $20^{\circ} \mathrm{S}$ to $20^{\circ} \mathrm{N}$ and throughout the depth of the 

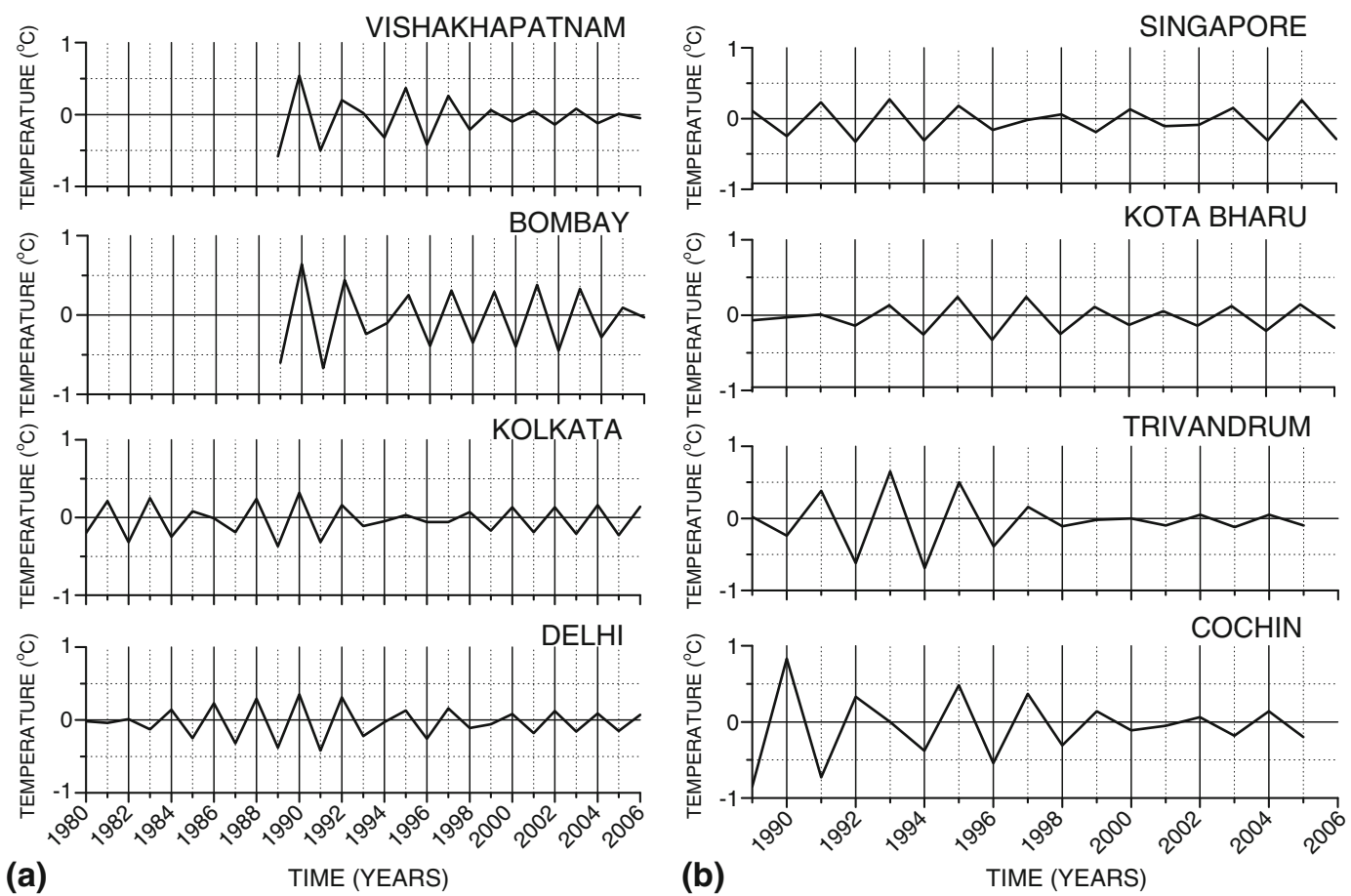

Figure 7. (a and b). Temporal variation of filtered temperature (only QBO signal retained) at 100-hPa level over a period of 1980-2006 at Delhi and Kolkata, during 1989-2006 at Bombay, Vishakhapatnam, Kota Bharu and Singapore, and from 1989-2005 at Cochin and Trivandrum.
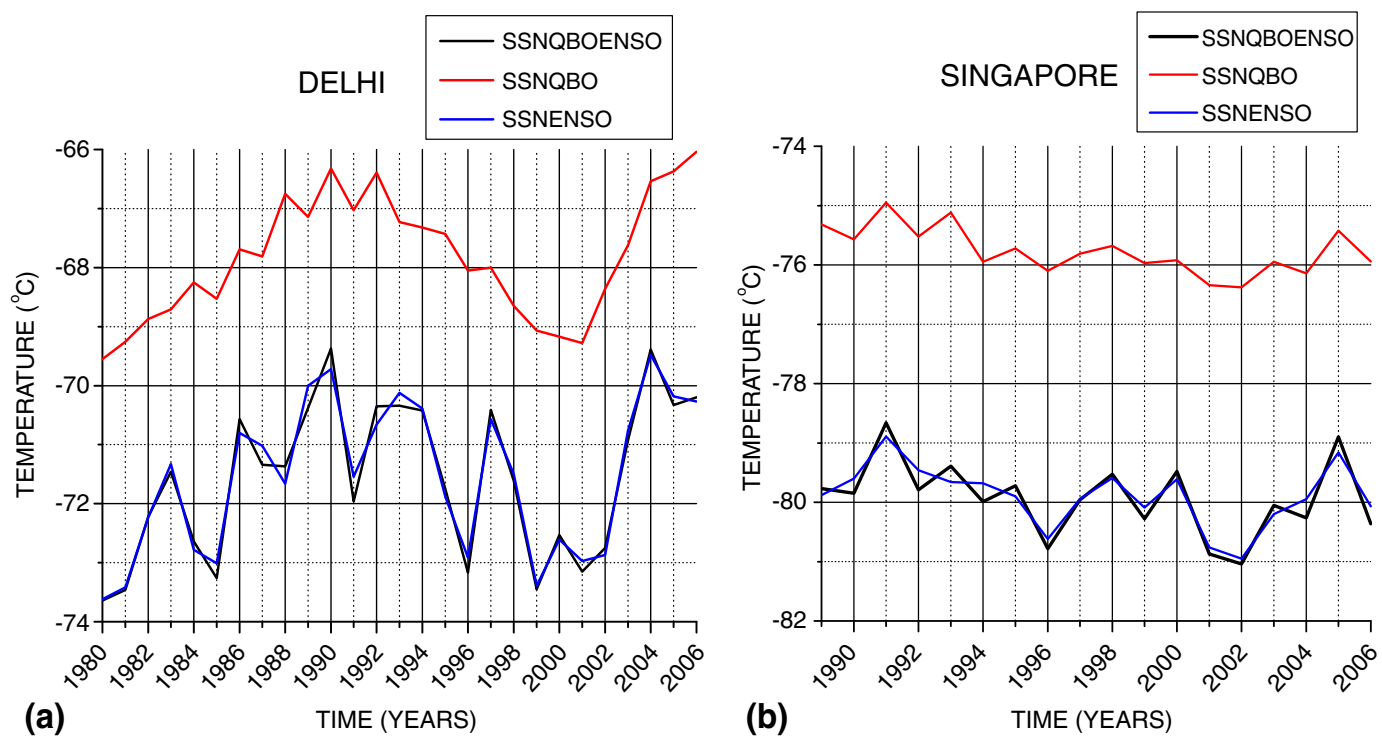

Figure 8. (a) Temporal variation of filtered temperature (solar cycle, QBO, and ENSO) at 100-hPa level over a period of 1980-2006 at Delhi. Black line denotes signals from solar cycle+QBO+ENSO, blue line represents solar cycle+ENSO, while red line denotes solar cycle+QBO. (b) Same as (a) but, at Singapore station.

stratosphere from 100 to $1.0 \mathrm{hPa}$. However, the present analysis showed QBO signal in the 100-hPa temperature even at slightly higher latitudes, i.e., $\sim 22^{\circ}-28^{\circ} \mathrm{N}$

We tried to separate the several signals by employing filter technique. Figure 8 ( $\mathrm{a}$ and $\mathrm{b}$ ) represents filtered temperature at $100-\mathrm{hPa}$ having contribution from the sum of solar cycle and $\mathrm{QBO}$ components (red line), solar cycle and ENSO components (blue line) and from the sum of solar cycle, QBO and ENSO components (black line) at Delhi and Singapore stations, respectively. The presence of QBO signal with lesser amplitude (as compared to equatorial stations) on stations away from equator, i.e., at Delhi and Kolkata indicates that QBO had affected the temperature variations at $100-\mathrm{hPa}$ 
level not only at equatorial region but extended up to the extra-tropical regions.

At Bombay $\left(19.11^{\circ} \mathrm{N}, 72.84^{\circ} \mathrm{E}\right)$ and Vishakhapatnam $\left(17.0^{\circ} \mathrm{N}, 83.30^{\circ} \mathrm{E}\right)$ stations, QBO signal (with amplitudes of $\sim \pm 0.5 \mathrm{~K}$ ) is prominently present during 1989-1996, which decreased substantially (i.e., $\sim \pm 0.1 \mathrm{~K}$ ) over a period 1997-2006. Around year 2000 and later, the decrease in water vapour and ozone are also the key issues in the lower stratosphere dynamics (Randel et al 2006). Solomon et al (2010) have shown a sharp and persistent drop in lower stratospheric water vapour of about 0.4 parts per million by volume (ppmv) after the year 2000 based on HALOE, balloonsonde, stratospheric aerosol and gas experiment II (SAGE II), and from the microwave limb sounder (MLS) instruments. Therefore, some changes in the dynamics could be due to the radiative forcing in the climate after year 2000. These changes are attributed for weakening the effect of QBO signal in temperature at these stations. It is also noted that, QBO contribution in the annual temperature increases while moving from Vishakhapatnam $\left(17^{\circ} \mathrm{N}\right)$ to Cochin $\left(10^{\circ} \mathrm{N}\right)$ suggesting that QBO has large amplitude $(\sim \pm 0.7 \mathrm{~K})$ over equator that decreases rapidly away from the equator. However, QBO signatures are not found stronger after 1996 at Cochin and Trivandrum stations, this is partly due to the strong solar cycle signal in the temperature variations (section 3.3.3). Pascoe et al (2005) observed that the 11-year solar cycle introduces inter-annual variations in the strength of the equatorial upwelling using wind data. This finding is similar to as our results in terms of solar cycle effect on temperature data and its inter-annual variability over $2-3$ decades.

In the eastern side of Bay of Bengal region, i.e., at Singapore and Kota Bharu stations, signature of $\mathrm{QBO}$ event is strong in temperature at $100-\mathrm{hPa}$ level. At Singapore $\left(1.36^{\circ} \mathrm{N}, 103.9^{\circ} \mathrm{E}\right)$ which is located near equator, temperature variations at $100-\mathrm{hPa}$ level are dominated by QBO $(\sim \pm 0.3 \mathrm{~K})$. Figure $8(\mathrm{~b})$ clarifies that QBO contribution is more in comparison to ENSO and solar cycle signals at Singapore. Also, QBO captures a large fraction of the inter-annual variance at Singapore in comparison to other stations. This result is in good agreement with Dunkerton and Delisi (1985). They derived the latitudinal structure of the QBO in zonal wind (see their figure 3, Baldwin et al 2001), using long time series of wind observations at many tropical stations and observed that the amplitude of the QBO is latitudinally symmetric $\left(20^{\circ} \mathrm{N}-20^{\circ} \mathrm{S}\right)$, and the maximum is centered over
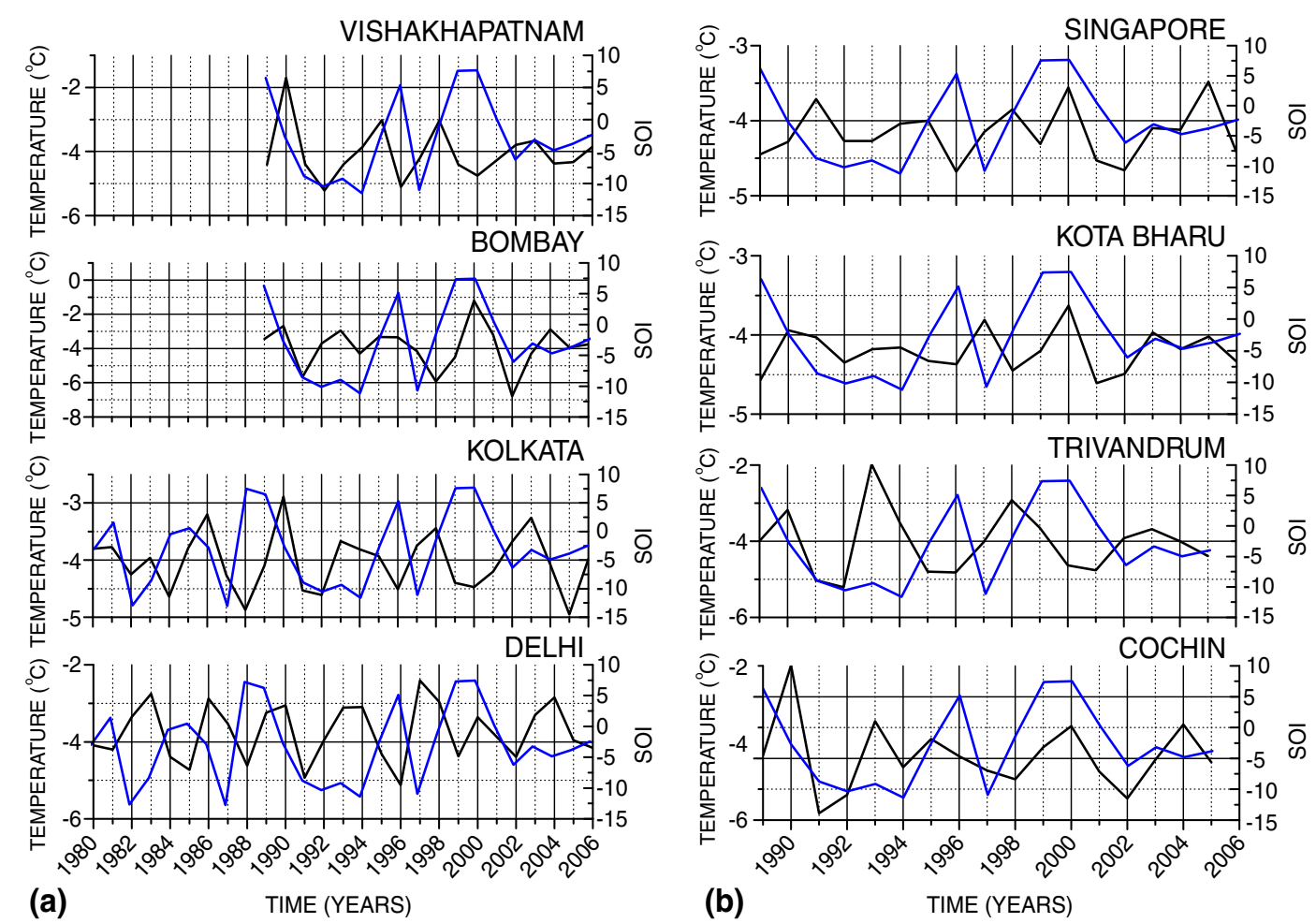

Figure 9. (a and b). Temporal variation of filtered temperature (only ENSO signal retained) at 100-hPa level (over a period of 1980-2006 at Delhi and Kolkata stations, 1989-2006 at Bombay, Vishakhapatnam, Kota Bharu and Singapore and during 1989-2005 at cochin and Trivandrum). Black lines denote filtered temperature (only ENSO signal retained) and blue lines denote standardized ENSO or SOl. 
the equator. The reason for $\mathrm{QBO}$ to be equatorially confined may be that it is driven by equatorially trapped waves (Baldwin et al 2001).

In our analysis, we found QBO signal in temperature at $100-\mathrm{hPa}(\sim 16 \mathrm{~km})$ with less amplitude in consonance with the fact that the amplitude decreases very fast between 22 and $17 \mathrm{~km}$ height. Moreover, positive tropopause temperature anomalies at $100-\mathrm{hPa}$ level are associated with positive (westerly) QBO winds (at Singapore, not shown here). This result is consistent with Randel et al (2000), as they reported similar features at 50 mbar. In addition, the consistency in the phase of the QBO is noted at all stations over Indian region confirming its appearance in the broad area.

\subsubsection{Signature of ENSO in temperature at 100-hPa level}

The response of ENSO signal in the temperature variations of tropopause region needs to be evaluated. Some earlier studies account for the presence of ENSO signatures in the temperature variations of the UTLS region (Yulaeva and Wallace 1994). They showed that the ENSO signal in lower stratospheric temperature is primarily evident in zonal variations in the tropics. Reid and Gage (1985) and Gage and Reid (1987) reported evidence of ENSO variations in tropical tropopause height and temperature. However, signature of ENSO in temperature is not examined over Indian region. Thus, in order to determine presence of ENSO component in the temperature over Indian and eastern side of Bay of Bengal region, we employed filter technique to retain periods between 2 and 7 years. Figure 9 ( $\mathrm{a}$ and $\mathrm{b}$ ) shows temporal variation of filtered temperature (only ENSO signal retained) at $100-\mathrm{hPa}$ with standardized SOI over a period of 1980-2006 at Delhi and Kolkata, during 1989-2006 over Bombay, Vishakhapatnam, Kota Bharu and Singapore and during 1989-2005 at Cochin and Trivandrum stations.

Observing the filtered temperature (only ENSO signal retained) at $100-\mathrm{hPa}$ level along with standardized SOI, we found that at Delhi and Kolkata, SOI is out of phase with filtered temperature indicating warm ENSO event results in tropopause heating over the Indian region. The ENSO signal is noted of the order of $\sim \pm 1 \mathrm{~K}$ at Delhi station. The significant anti-correlation at Delhi (see table 3) between temperature and SOI further confirms the out of phase relation between these two. It may be noted that, during ENSO warm events there is a shift in convection from Indonesia towards the east, which leads to warming in eastern Pacific sea surface temperatures. Such shifting leads to the tropopause cooling possibly due to enhanced
Table 3. Correlation coefficients between annual filtered temperature (only ENSO signal retained) at 100-hPa level and standardized SOI. Bold values of $R_{\mathrm{xy}}$ are statistically significant (using student's t-test) at 1\% significance level.

\begin{tabular}{lc}
\hline Stations & Correlation coefficient $\left(R_{\mathrm{xy}}\right)$ \\
\hline Delhi & $\mathbf{- 0 . 3 9}$ \\
Kolkata & -0.19 \\
Bombay & 0.34 \\
Vishakhapatnam & -0.10 \\
Cochin & 0.29 \\
Trivandrum & -0.14 \\
Kota Bharu & -0.12 \\
Singapore & -0.12 \\
Darwin & $\mathbf{- 0 . 5 3}$ \\
\hline
\end{tabular}

vertical motions near $140^{\circ} \mathrm{W}$, and the tropopause warming near $140^{\circ} \mathrm{E}$ (Randel et al 2000). Our analyses in the Indian region validate the results of Randel et al (2000). This indicates that interaction between atmosphere and ocean is evident even at far distances such as at Delhi station (Indian region) following the similar patterns as noted in Indonesian region.

On the other hand, at stations located around $15^{\circ}-20^{\circ} \mathrm{N}$ such as Kolkata and Vishakhapatnam, no significant correlation was observed between temperature and SOI. This is because of the fact that these stations are under the influence of intense local convection (as they are located near Bay of Bengal - a highly convective zone) with strong diurnal variations, which may possibly suppress the effect coming from the large scale oscillations such as ENSO. Another contributing factor could be due to the presence of strong easterly jet around $20^{\circ} \mathrm{N}$ which can dominate over ENSO signatures.

At Cochin and Trivandrum stations, correlation coefficient between filtered temperature (only ENSO signal retained) and SOI is insignificant. This is because solar cycle effect is maximum near equatorial region (i.e., at Cochin and Trivandrum, shown in section 3.3.3). Such features are similar to as found by Chun et al's (2007) analysis of satellite data. They suggested that deep convective heating in annual mean is maximum at $8^{\circ} \mathrm{N}$ (see their figure 2) using global data. It appears that due to strong solar cycle influence around $8^{\circ}-10^{\circ} \mathrm{N}$, contribution of all other components (such as QBO and ENSO) is suppressed. Thus, ENSO signal is not prominent in the temperature at $100-\mathrm{hPa}$ level at Trivandrum. Further, on comparison, it is found that ENSO contribution $(\sim \pm 1 \mathrm{~K})$ is as twice as the contribution of $\mathrm{QBO}(\sim \pm 0.4 \mathrm{~K})$ in annual temperature at all stations over India. This is in accordance with the result that, El Niño events are characterized by major shifts in the location and strength of tropical convection across the 


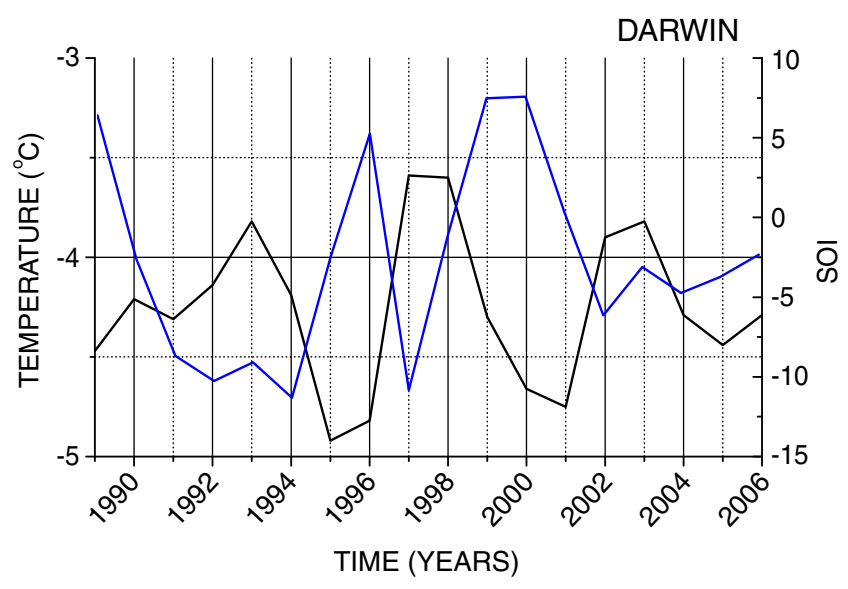

Figure 10. Temporal variation of filtered temperature (only ENSO signal retained) at 100-hPa level during 1989-2006 at Darwin. Black line denote ENSO signal in temperature and blue line denote standardized SOl.

entire Pacific and most major monsoon regions of the world (Bell and Halpert 1998). Such changes in convective activity could influence the QBO through changes in the gravity wave spectrum initiated by deep tropical convection. Such gravity waves are thought to be an important QBO driving mechanism (Dunkerton 1997). Therefore, ENSO can have a tendency to modulate the QBO signal.

In addition, we have examined the contribution of ENSO component in 100-hPa temperature over Darwin $\left(12.4^{\circ} \mathrm{S}, 130.88^{\circ} \mathrm{E}\right)$ located in the southern hemisphere. Temporal variation of filtered temperature (only ENSO signal retained) at $100-\mathrm{hPa}$ level with standardized SOI over a period of 19892006 at Darwin is shown in figure 10. It is noted that ENSO warm events are associated with heating of the tropopause region similar to as found over Delhi station. Moreover, $R_{\mathrm{xy}}(\sim-0.53)$ and the amplitude $(\sim \pm 1.2 \mathrm{~K})$ of the ENSO signal is significantly large at Darwin suggesting the presence of strong ENSO signal in the temperature at $100-\mathrm{hPa}$ level. This result matches well with the analysis of Randel et al (2000).

\subsubsection{Relationship between temperature at 100-hPa level and solar cycle}

In sections 3.3.1 and 3.3.2, dominance of $\mathrm{QBO}$ and ENSO variations in temperature at $100-\mathrm{hPa}$ level is observed over eight stations located in the Indian and eastern side of the Bay of Bengal region. Comprehensive analysis of the influence of solar cycle component in temperature is studied in this section. Dhaka et al (2010) observed that solar cycle signal get strong if we move from Delhi to Trivandrum (i.e., moving towards equator) and modulate the temperature field on 11 years time-scale most effectively in $8^{\circ}-10^{\circ} \mathrm{N}$ latitude range. This investigation is extended by including four more stations, i.e., Bombay and Vishakhapatnam over India, and Kota Bharu and Singapore in the eastern side of the Bay of Bengal region.

Figure 11 ( $a$ and $b$ ) shows the annual variation of temperature at $100-\mathrm{hPa}$ level with solar cycle over a period 1980-2006 at Delhi and Kolkata, from 1989-2006 at Bombay, Vishakhapatnam, Kota Bharu and Singapore and during 1989-2005 at Cochin and Trivandrum stations. Latitudinal variability of temperature with solar cycle is observed. Solar cycle modulation on temperature is clearly seen at Bombay, Vishakhapatnam, Cochin and Trivandrum. But, influence of solar cycle on temperature is found to be significant only at Cochin and Trivandrum.

Correlation coefficient $\left(R_{\mathrm{xy}}\right)$ between yearly averaged temperature at $100-\mathrm{hPa}$ level and solar cycle is computed at all stations. At Delhi and Kolkata, $R_{\mathrm{xy}}$ is negative and insignificant, whereas at all other stations $R_{\mathrm{xy}}$ is positive (see table 4 , column 2). This is because; at Delhi and Kolkata stations there is a close relation between convection in the lower atmosphere and temperature in the upper atmosphere irrespective of solar cycle influence (Dhaka et al 2010). Also, at Delhi station, QBO and ENSO signals are present in the 100-hPa temperature data. Due to the influence of these geophysical phenomena on temperature, solar cycle effect is not significantly seen at Delhi. Over Kolkata, QBO and ENSO signals are weak in comparison to Delhi. Note that, diurnal variability in convection is strong over Kolkata, which could dominate over solar cycle. However, $R_{\mathrm{xy}}$ is significant only at Cochin and Trivandrum stations, i.e., around $8^{\circ}-10^{\circ} \mathrm{N}$ and insignificant at all other stations over Indian and eastern side of the Bay of Bengal region. This extended result compares well with the analysis of Dhaka et al (2010) that shows positive good correlation seen in the equatorial region maximizing around $8^{\circ}-10^{\circ} \mathrm{N}$.

\subsubsection{Solar cycle signatures in temperature (filtered) at 100-hPa level}

In this section, an attempt is made to estimate the independent contribution of solar cycle component by removing the effects of other components such as QBO, ENSO, etc., from the 100-hPa temperature data. Dhaka et al (2010) had not analyzed the dominance of individual solar cycle component by removing all other components from the temperature at $100-\mathrm{hPa}$ level. In order to individually examine solar cycle variability in temperature, we isolate the solar cycle signal by filtering out the other components from the temperature 

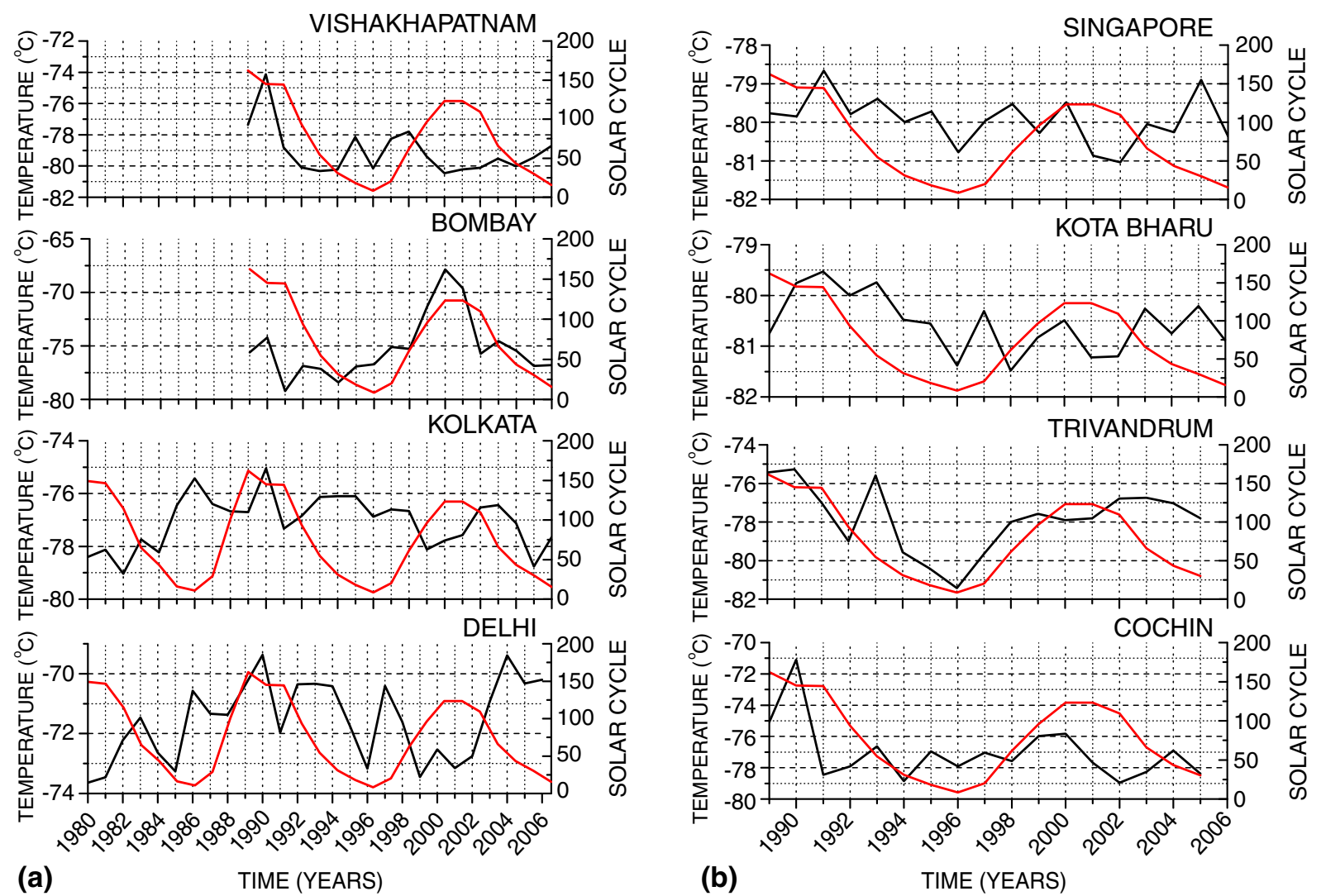

Figure 11. (a and b). Temporal variation of yearly averaged temperature at 100-hPa pressure level with solar cycle (from 1980-2006 at Delhi and Kolkata, during 1989-2006 at Bombay, Vishakhapatnam, Kota Bharu and Singapore and from 1989 to 2005 at Cochin and Trivandrum). Red lines denote sunspot numbers, while black line denotes temperature.

Table 4. Correlation coefficients of annual temperature data and filtered temperature (solar cycle retained) at 100-hPa level with solar cycle over Delhi, Kolkata, Bombay, Vishakhapatnam, Cochin, Trivandrum, Kota Bharu and Singapore stations. Bold values of $R_{\mathrm{xy}}$ are statistically significant (using student's t-test) at 1\% significance level.

\begin{tabular}{lcc}
\hline & $\begin{array}{c}\text { Correlation coefficient } \\
\left(R_{\mathrm{xy}}\right) \text { between annually } \\
\text { averaged temperature at } \\
\text { 100-hPa and solar cycle }\end{array}$ & $\begin{array}{c}\text { Correlation coefficient }\left(R_{\mathrm{xy}}^{1}\right) \\
\text { between filtered temperature } \\
\text { (solar cycle retained) at } \\
\text { 100-hPa and solar cycle }\end{array}$ \\
\hline Delhi & -0.25 & -0.26 \\
Kolkata & -0.25 & -0.29 \\
Bombay & 0.38 & $\mathbf{0 . 4 5}$ \\
Vishakhapatnam & 0.29 & $\mathbf{0 . 4 0}$ \\
Cochin & $\mathbf{0 . 4 4}$ & $\mathbf{0 . 7 6}$ \\
Trivandrum & $\mathbf{0 . 6 8}$ & 0.84 \\
Kota Bharu & 0.21 & 0.21 \\
Singapore & 0.12 & \\
\hline
\end{tabular}

time series. Figure 12 (a and b) shows the temporal variation of filtered temperature (solar cycle signal retained) at $100-\mathrm{hPa}$ level along with solar cycle over eight stations located in the Indian and eastern side of the Bay of Bengal region.

Now, large solar modulation in temperature is found at Bombay, Vishakhapatnam, Cochin and
Trivandrum. $R_{\mathrm{xy}}$ between temperature at $100-\mathrm{hPa}$ level and solar cycle improves considerably after removing all other components (QBO, ENSO, etc.) except solar cycle from 100-hPa temperature data. $R_{\mathrm{xy}}$ values imply that there is significant positive correlation (see table 4, column 3 ) exist at Bombay, Vishakhapatnam, Cochin and Trivandrum, 

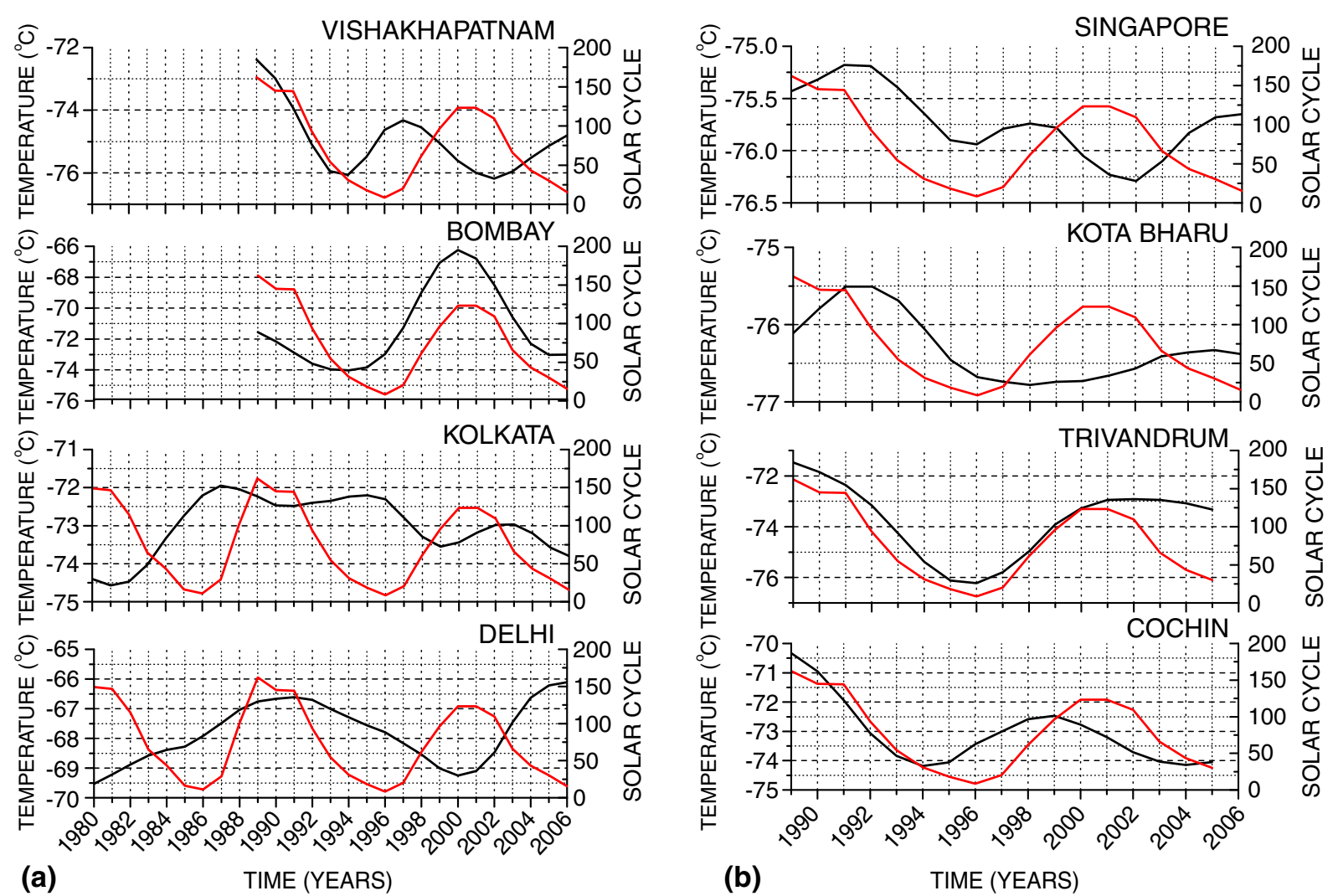

Figure 12. (a and b). Temporal variation of filtered temperature (solar cycle signal retained) at 100-hPa pressure level with solar cycle (from 1980-2006 at Delhi and Kolkata, during 1989-2006 at Bombay, Vishakhapatnam, Kota Bharu and Singapore and from 1989 to 2005 at Cochin and Trivandrum). Red lines denote solar variability in temperature, while black lines denote filtered temperature.

maximizes around $8^{\circ}-10^{\circ} \mathrm{N}$. This result conforms to the fact that the solar radiation pattern decreases sharply on moving towards middle and higher latitudes, i.e., away from equatorial region (Chun et al 2007). Therefore, the influence of solar cycle on the temperature decreases on moving towards Bombay and Vishakhapatnam (located away from equator) in comparison to Cochin and Trivandrum stations.

Figure 13 shows the latitudinal variation of correlation coefficient $\left(R_{\mathrm{xy}}\right)$ between filtered temperature (solar cycle signal retained) at $100-\mathrm{hPa}$ level and solar cycle at eight stations located over $0^{\circ}-30^{\circ} \mathrm{N}$. It is evident from figure 13 that $R_{\mathrm{xy}}$ is positive at all stations except at Delhi and Kolkata. $R_{\mathrm{xy}}$ remains negative and insignificant at Delhi and Kolkata, suggesting no solar cycle influence in $100-\mathrm{hPa}$ temperature at these stations. This further elucidates the conditions for the existence of both ENSO and QBO signals at Delhi, and thus suggests that there has been a mutual competition between these parameters (QBO, ENSO, and solar cycle effect) from the equator to the extra-tropical region. Table 5 gives the relative contribution of each signal (QBO, ENSO, and solar cycle) at different stations. Different colour code

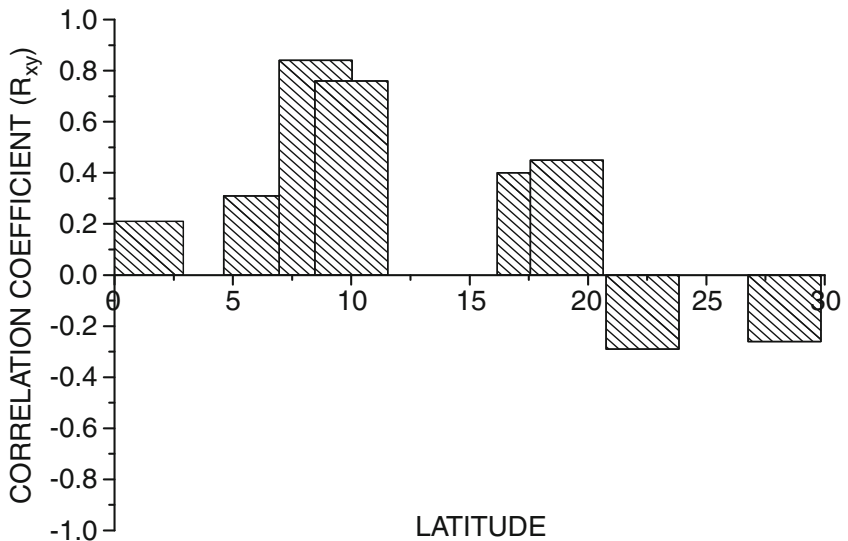

Figure 13. Correlation coefficients $\left(R_{\mathrm{xy}}\right)$ between filtered temperature (solar cycle signal retained) at 100-hPa level and solar cycle at Delhi, Kolkata, Bombay, Vishakhaptnam, Cochin, Trivandrum, Kota Bharu and Singapore stations located over $0^{\circ}-30^{\circ} \mathrm{N}$ covering Indian and eastern side of Bay of Bengal region.

denotes the intensity of the signals, while moving from low latitudes to middle latitudes.

Comparison of correlation coefficients for these analyses (sections 3.3.3 and 3.3.4) is shown in 
Table 5. Relative contribution of QBO, ENSO and solar cycle signals in 100hPa temperature over different stations. Intensity of the colour codes show strength of the signal while moving from low latitudes to middle latitudes. Dark blue represents strong QBO and ENSO, while strong solar cycle signal is denoted by red color. The strong presence of solar cycle signal at equatorial stations suppresses the $Q B O$ and ENSO signals strength.

\begin{tabular}{|c|c|c|c|}
\hline Stations & QBO effect & ENSO effect & Solar cycle effect \\
\hline Delhi & (moderate) & $\widehat{U}$ (moderate) & \\
\hline Kolkata & (weak) & & \\
\hline Bombay & & & (moderate) \\
\hline Vishakhapatnam & & & $\checkmark$ (moderate) \\
\hline Cochin & & & (strong) \\
\hline Trivandrum & & & (strong) \\
\hline Kota Bharu & $\int($ moderate $)$ & & \\
\hline Singapore & (strong) & & \\
\hline
\end{tabular}

table 4. It is clear from the table that the magnitude of $R_{\mathrm{xy}}$ increases considerably at Bombay, Vishakhapatnam, Cochin and Trivandrum after filtering out all components from the temperature except solar cycle.

Solar cycle component in temperature is present over tropical and equatorial region of India; however, the influence is not clear at Kota Bharu and Singapore stations indicating that QBO and ENSO components may dominate over solar cycle at these stations. Thus, we conclude that solar cycle effect on temperature at $100-\mathrm{hPa}$ pressure level is dominating over tropical and equatorial regions with strong control around $8^{\circ}-10^{\circ} \mathrm{N}$.

\section{Summary and discussions}

We have shown relationship of OLR with CAPE and temperature at $100-\mathrm{hPa}$ pressure level at Delhi, Kolkata, Cochin and Trivandrum stations. All the four stations are geographically located at different locations. OLR and CAPE are found to be anti-correlated at Delhi and Kolkata indicating that low OLR represents the enhanced convective activity. However, no significant relation exists between OLR and CAPE over Cochin and Trivandrum. The modulation of OLR and CAPE relation towards low latitude is due to the northward $\left(\sim 20^{\circ}-24^{\circ} \mathrm{N}\right)$ movement of ITCZ. On the other hand, OLR and temperature showed significant positive correlation over Delhi and Kolkata with maximum value at Delhi. But, the positive $R_{\mathrm{xy}}$ becomes negative on moving towards Cochin and Trivandrum stations. At low latitudes, there is a strong solar cycle influence on temperature at
100-hPa level, which modifies OLR and temperature relationship. Solar cycle dominance is further confirmed when correlation between OLR and temperature improved significantly after removal of solar cycle component from the temperature data. Thus, $R_{\mathrm{xy}}$ between OLR and temperature at Cochin and Trivandrum improved in the same order as Delhi and Kolkata. Removal of solar cycle from the temperature data and subsequent improvement in $R_{\mathrm{xy}}$ between OLR and temperature suggest that solar cycle signal is dominating over $8^{\circ}-10^{\circ} \mathrm{N}$, thus modulating the dynamics over large scale.

In recent studies, Jain et al (2010, 2011) observed strong association between low OLR and low $\mathrm{T}_{100}$ over the Bay of Bengal region (using $\sim 2$ months data), and between low OLR and low CPT temperature over the Arabian side (using $\sim 1$ year data). Our results confirms that such relationship of OLR with temperature at 100-hPa level operates on different time scales (including seasonal and decadal) over Indian region. We have further extended this analysis by annually averaging OLR, CAPE and temperature data; it is found that OLR-CAPE and OLR-temperature relationship is based on the seasonal variations because $R_{\mathrm{xy}}$ turns insignificant for annually averaged values, which is an important finding. Thus, this analysis suggests that seasonal variability is dominating in OLR-CAPE and OLR-temperature relationship.

In order to reveal the QBO, ENSO and solar cycle variability in $100-\mathrm{hPa}$ temperature data we included four more stations: Bombay, Vishakhapatnam, Kota Bharu and Singapore. By analyzing the data for several stations spread over Indian region, we noted variation in the strength of $\mathrm{QBO}$ 
and ENSO signals with a bias of strong QBO near equator (during 1989-1996, note that after 1996 it showed a tendency of weak signal) and strong ENSO over Delhi (away from equator). Such weakening of the QBO signal, after 1996, may be partly due to the presence of strong solar cycle signature at equatorial stations. Some influence on the dynamics could be from the change in the radiative forcing after the year 2000 as discussed by Solomon et al (2010). However, the presence of QBO signal on stations away from equator, i.e., at Delhi and Kolkata (with lesser amplitude than at equatorial stations) indicates that QBO had affected the temperature variations at $100-\mathrm{hPa}$ level not only at equatorial region but it extended up to the extra-tropical region.

Weak QBO and ENSO signals are observed at stations, which are located around $15^{\circ}-20^{\circ} \mathrm{N}$ such as Kolkata and Vishakhapatnam. This is due to the fact that these stations are under the influence of intense local convection with strong diurnal variations which may possibly suppress the effect coming from the large scale oscillations. Another contributing factor could be due to the presence of strong easterly jet around $20^{\circ} \mathrm{N}$ which can weaken the signature of both QBO and ENSO. This is possibly through gravity wave generation and their subsequent upward propagation. Over the eastern side of Bay of Bengal region, QBO signal is observed both at Singapore and Kota Bharu stations. But, it is stronger at Singapore as compared to Kota Bharu. This is in accordance with the reason that QBO is nearly symmetrical with respect to the equator since, it is driven by equatorially trapped waves. The amplitude decreases fast as we go further away from the equator.

In addition, ENSO is found to be out of phase $\left(\sim 180^{\circ}\right)$ with temperature in the tropopause region at Delhi, suggesting tropopause warming during ENSO warm event. At Darwin station located in the southern hemisphere, ENSO signal is dominating in the temperature variations and it is stronger at Darwin $(\sim \pm 1.2 \mathrm{~K})$ in comparison to other stations shown in this study indicating warm ENSO event leads to tropopause warming suggesting remote forcing at long distances. Moreover, in general, ENSO contribution $(\sim \pm 1 \mathrm{~K})$ is as twice as the $\mathrm{QBO}$ contribution $(\sim \pm 0.4 \mathrm{~K})$ in annual temperature over Indian region, because the shift in convective regime that is induced by ENSO, influences the QBO through changes in the gravity wave spectrum initiated by deep tropical convection. Therefore, ENSO can have a tendency to modulate the QBO signal.

In order to examine the individual solar cycle variability in $100-\mathrm{hPa}$ temperature data, we filtered out all other components (QBO, ENSO, etc.) except solar cycle and it is found that the correlation coefficient between filtered temperature (solar cycle signal retained) at $100-\mathrm{hPa}$ level and sunspot numbers becomes significantly positive at Bombay, Vishakhapatnam, Cochin and Trivandrum and the magnitude of $R_{\mathrm{xy}}$ is maximum at Cochin and Trivandrum. This is in well agreement with the findings of Chun et al (2007) and Dhaka et al (2010). Since, there is a sharp decrease in solar radiation pattern on moving towards middle and higher latitudes. Thus, we have found that the solar cycle influence in the temperature decreases on moving towards Bombay and Vishakhapatnam in comparison to Cochin and Trivandrum stations. The relationship between solar cycle and temperature became insignificant at Delhi, Kolkata, Kota Bharu and Singapore stations suggesting lesser influence of solar cycle. As solar cycle effect is not prominent at Delhi station, therefore, under such conditions both ENSO and QBO signals came up strongly. We noticed that there has been a mutual competition between these parameters (QBO, ENSO, and solar cycle effect) from the equator to the extra-tropical region. Furthermore, the comparison of correlation coefficients between annually averaged temperature and solar cycle with filtered temperature (solar cycle signal retained) and solar cycle indicates that the magnitude of $R_{\mathrm{xy}}$ increases at Bombay, Vishakhapatnam, Cochin and Trivandrum stations after filtering the temperature data. This suggests that solar cycle signal modulates the temperature variations over middle and lower latitudes, however strong solar variability in temperature is found around $8^{\circ}-10^{\circ} \mathrm{N}$. Thus, we conclude that the large scale oscillations such as QBO, ENSO and solar cycle are present in the upper troposphere temperature variations; however their respective contribution (in terms of amplitude) varies depending on the location of the observed station.

\section{Acknowledgements}

The authors are thankful to India Meteorological Department (IMD), Delhi for providing radiosonde data. Data for solar cycle and ENSO are taken from http://www.nasa.gov. S K Dhaka acknowledges RESPOND-ISRO, India for support under CAWSES program.

\section{References}

Baldwin M P, Gray L J, Dunkerton T J, Hamilton K, Haynes P H, Randel W J, Holton J R, Alexander M J, Hirota I, Horinouchi T, Jones D B A, Kinnersley J S, Marquardt C, Sato K and Takahasi M 2001 The Quasi-Biennial Oscillation; Rev. Geophys. 39 179-229. 
Bell G D and Halpert M S 1998 Climate assessment for 1997; Bull. Amer. Meteorol. Soc. 79(5) S1-S50.

Chun H-Y, Goh J-S, Song I-S and Riccardulli L 2007 Latitudinal variations of the convective sources and propagation condition of Inertia-gravity waves in the tropics; J. Atmos. Sci. 64 1603-1616.

Dhaka S K, Sapra R, Panwar V, Goel A, Bhatnagar R, Kaur M, Mandal T K, Jain A R and Chun H-Y 2010 Influence of large-scale variations in convective available potential energy (CAPE) and solar cycle over temperature in the tropopause region at Delhi $\left(28.3^{\circ} \mathrm{N}\right.$, $\left.77.1^{\circ} \mathrm{E}\right)$, Kolkata $\left(22.3^{\circ} \mathrm{N}, 88.2^{\circ} \mathrm{E}\right)$, Cochin $\left(10^{\circ} \mathrm{N}, 77^{\circ} \mathrm{E}\right)$ and Trivandrum $\left(8.5^{\circ} \mathrm{N}, 77.0^{\circ} \mathrm{E}\right)$ using radiosonde during 1980-2005; Earth Planets Space 62 319-331.

Dunkerton T J 1997 The role of gravity waves in the quasi-biennial oscillation; J. Geophys. Res. 102(D22) $26,053-26,076$.

Dunkerton T J and Delisi D P 1985 Climatology of the equatorial lower stratosphere; J. Atmos. Sci. 42 $376-396$.

Gage K and Reid G 1987 Longitudinal variations in tropical tropopause properties in relation to tropical convection and ENSO events; J. Geophys. Res. 92 14,197$14,203$.

Gettelman A, Seidel D J, Wheeler M C and Ross R J 2002 Multidecadal trends in tropical convective available potential energy; J. Geophys. Res. 107(D21) 4606.

Gray L J, Phipps S J, Dunkerton T J, Baldwin M P, Drysdale E F and Allen M R 2001 A data study of the influence of the equatorial upper stratosphere on northern-hemisphere stratospheric sudden warmings; Quart. J. Roy. Meteorol. Soc. 127 1985-2003.

Holton J R, Curry J H and Payle J A 2003 Inter Tropical Convergence Zone; Encyclopedia of Atmospheric Science $62325-2334$.

Jain A R, Panwar V, Mandal T K, Rao V R, Goel A, Gautam R, Das S S and Dhaka S K 2010 Mesoscale convection system and occurrence of extreme low tropopause observations over Asian summer monsoon region; Ann. Geophys. 28 927-940.

Jain A R, Panwar V, Johny C J, Mandal T K, Rao V R, Gautam R and Dhaka S K 2011 Occurrence of extremely low cold point tropopause temperature during sum- mer monsoon season: ARMEX campaign and CHAMP/ COSMIC satellite observations; J. Geophys. Res. 116 D03102, doi: 10.1029/2010JD014340.

Mc Bridge J L and Frank W M 1999 Relationship between stability and monsoon convection; J. Atmos. Sci. 56 $24-56$.

Naujokat B 1986 An update of the observed quasi-biennial oscillation of the stratospheric winds over the tropics; J. Atmos. Sci. 43 1873-1877.

Pascoe C L, Gray L J, Crooks S A, Juckes M N and Baldwin M P 2005 The quasi-biennial oscillation: Analysis using ERA-40 data; J. Geophys. Res. 110 D08105, doi: 10.1029/2004JD004941.

Randel W J, Wu F, Swinbank R, Nash J and O'Neill A 1999 Global QBO circulation derived from UKMO stratospheric analyses; J. Atmos. Sci. 56 457-474.

Randel W J, Wu Fei and Gaffen D J 2000 Interannual variability of the tropical tropopause derived from radiosonde data and NCEP reanalyses; J. Geophys. Res. 105(D12) $15,509-15,523$.

Randel W J, Wu F, Vömel H, Nedoluha G E and Forster P 2006 Decreases in stratospheric water vapor after 2001: Links to changes in the tropical tropopause and the Brewer-Dobson circulation; J. Geophys. Res. 111 D12312, doi: 10.1029/2005JD006744.

Reid G and Gage K 1985 Interannual variations in the height of the tropical tropopause; J. Geophys. Res. 90 56295635 .

Roy Bhowmik S K, Roy S S and Kundu P K 2008 Analysis of large-scale conditions associated with convection over the Indian region; Int. J. Clim. 28 797-821.

Solomon S, Karen H Rosenlof, Robert W Portmann, John S Daniel, Sean M Davis, Todd J Sanford and Gian-Kasper Plattner 2010 Contributions of stratospheric water vapor to decadal changes in the rate of global warming; Science 327 1219-1223.

Williams E R and Renno N O 1993 An analysis of the conditional instability of the tropical atmosphere; Mon. Weather Rev. 121 21-36.

Yulaeva E and Wallace J M 1994 The signature of ENSO in global temperature and precipitation fields derived from the microwave sounding unit; J. Climate 7 17191736. 